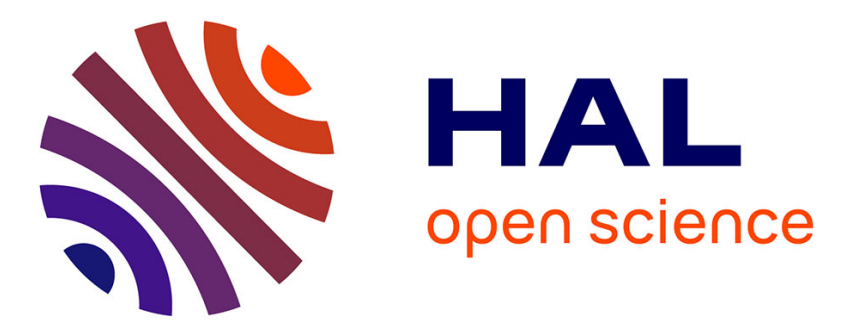

\title{
Drug utilisation on a preterm and neonatal intensive care unit in Germany: a prospective, cohort-based analysis
}

Antje Neubert, Kristin Lukas, Thomas Leis, Harald Dormann, Kay Brune, Wolfgang Rascher

\section{To cite this version:}

Antje Neubert, Kristin Lukas, Thomas Leis, Harald Dormann, Kay Brune, et al.. Drug utilisation on a preterm and neonatal intensive care unit in Germany: a prospective, cohort-based analysis. European Journal of Clinical Pharmacology, 2009, 66 (1), pp.87-95. 10.1007/s00228-009-0722-8 . hal-00534992

\section{HAL Id: hal-00534992 \\ https://hal.science/hal-00534992}

Submitted on 11 Nov 2010

HAL is a multi-disciplinary open access archive for the deposit and dissemination of scientific research documents, whether they are published or not. The documents may come from teaching and research institutions in France or abroad, or from public or private research centers.
L'archive ouverte pluridisciplinaire HAL, est destinée au dépôt et à la diffusion de documents scientifiques de niveau recherche, publiés ou non, émanant des établissements d'enseignement et de recherche français ou étrangers, des laboratoires publics ou privés. 


\title{
Drug utilisation on a preterm and neonatal intensive care unit in Germany: a prospective, cohort-based analysis
}

\author{
Antje Neubert • Kristin Lukas • Thomas Leis • \\ Harald Dormann $\cdot$ Kay Brune $\cdot$ Wolfgang Rascher
}

Received: 12 May 2009 / Accepted: 16 August 2009/Published online: 16 September 2009

(C) Springer-Verlag 2009

\begin{abstract}
Purpose This study aims to describe the drug use on a Neonatal Intensive Care Unit (NICU) at a University Children's Hospital in Germany, to investigate the licensing status of the drugs used and to conclude critical areas in neonatal intensive care to support prioritisation of future research.

Methods An 11-month, prospective cohort study was conducted on the NICU at the University Children's Hospital Erlangen, Germany. All products prescribed during the study period were analysed whether or not the SPC contains information on term and preterm neonates. Results A total of 183 patients (102 male) with a mean gestational age of 33.6 weeks (minimum $=24$, maximum $=42$ ) were included. The mean length of hospitalisation was 19.4 days $($ minimum $=2$, maximum $=167$ ). On average,
\end{abstract}

\section{A. Neubert $(\square)$}

Centre for Paediatric Pharmacy Research,

The School of Pharmacy and Institute of Child Health,

University of London,

29-39 Brunswick Square,

London WC1N 1AX, UK

e-mail: antje.neubert@pharmacy.ac.uk

K. Lukas $\cdot$ T. Leis $\cdot$ W. Rascher

Department of Paediatric and Adolescent Medicine,

Friedrich-Alexander University Erlangen-Nuremberg,

Erlangen, Germany

\section{H. Dormann}

Department of Medicine 1,

Friedrich-Alexander-University Erlangen-Nuremberg,

Erlangen, Germany

\section{K. Brune}

Department of Experimental and Clinical

Pharmacology and Toxicology,

Friedrich-Alexander University Erlangen-Nuremberg,

Erlangen, Germany patients received 11.1 drugs (minimum $=0$, maximum $=46$ ). The majority of prescriptions were accounted for by antibiotics ( $n=515)$, which were received by $90 \%$ of all patients, followed by CNS drugs $(n=448)$ and respiratory drugs $(n=$ $306)$. Of all the different drugs prescribed $(n=102)$ only $38 \%$ had information regarding their use in patients aged less than 1 month in their SPC. Analgesics and cardiovascular drugs were prescribed frequently, but without having information for use in neonates. Seventy percent of all patients and 100\% of very preterm infants received at least one of these drugs. Conclusions Treatment strategies on a preterm intensive care unit are complex and little information is available for the drugs used. Analgesics and cardiovascular drugs are of major concern. Efforts will have to be made to conduct welldesigned and powered studies in this vulnerable population.

Keywords Drug utilisation - Preterm - Neonates .

Neonatal intensive care unit · Unlicensed · Off-label

\section{Background}

Neonates and in particular preterm and very preterm neonates belong to the most vulnerable population. Very preterm neonates initially have to survive whereas older neonates are often admitted to the NICU because of congenital diseases and peri- or post-natal complications. Organ immaturity and consequently difficulties adapting to extra-maternal life are reasons for very preterm neonates being often multi-morbid and in need of intensive and complex medical care. Consequently, they are exposed to high numbers of drugs, putting them at higher risk of adverse drug reactions.

In recent years, major advances have been made in the pharmacological treatment of pre-term neonates, the average number of drugs administered per infant in neonatal 
intensive care units has been increasing over the last 40 years [1]. Survival of very preterm newborns has improved; thus, clinicians face more patients with complications in this group and strategies to reduce long-term morbidity have to be developed [2].

Although it has been shown that patterns of drug utilisation in neonatal intensive care are changing dynamically $[1,3]$, current data on drug utilisation patterns in neonatal intensive care units are limited [3, 4].

Initiatives in the US and in Europe as well as at the WHO level aim to promote research in the paediatric population [5-8]; however, recent research indicates that a large number of drugs used in neonatology are still unlicensed or off-label [9].

We conducted this study to:

1. Quantify the drug use on a neonatal intensive care unit (NICU) specialised in preterm infants at a University Children's Hospital in Germany

2. To identify drugs most frequently used

3. To investigate the extent of information available for this population in the Summary of Product Characteristics (SPC).

4. To conclude critical areas in neonatal intensive care to support prioritisation of future research

\section{Subjects and methods}

Study cohort

Data have been collected over an 11-month period (December 2004 to October 2005). Within the study period all patients admitted to the Neonatal Intensive Care Unit (NICU) at the University Children's Hospital Erlangen, Germany were included in the study population. Patients who stayed at the ward for less than $24 \mathrm{~h}$ have not been included. Once patients have been discharged or transferred to other wards, e.g. Neonatal Observation Ward and other hospitals, no further data have been collected. The study has been approved by the local Ethics Committee of the Medical Faculty of the University Erlangen-Nuremberg.

Data collection

From all patients demographic data, e.g. date of birth, weight at birth and gestational age, and all drug prescriptions on the ward, were prospectively recorded. Medicines given prior to presentation at the ward, e.g. in the delivery room, were retrospectively taken from the patient record (in-house referrals) or discharge letter (transferred patients).

Data regarding the following were not collected: continuous intravenous infusions, e.g. glucose or chloride, total parenteral nutrition and oxygen administration. All drugs prescribed have been documented by product name (according to the Hospital drug list), generic name and ATC Code.

Assessment of licensing status

All products prescribed during the study period were analysed whether or not any information regarding their use in patients aged less than 1 month was provided within the Summary of Product Characteristics (SPC, Fachinformation in Germany). If no information was given the drug was classified as off-label for the study population. Drugs that were imported and chemicals prepared into a formulation within the hospital pharmacy were classified as unlicensed [10]. Since prescribing in Germany is mainly done generically, the SPCs from the products supplied from our hospital pharmacy at the time of the study were analysed.

Statistical analysis

Patients were classified as very preterm (24th-27th week of gestation), preterm (28th-36th weeks of gestation) or terminfant ( $\geq 37$ th week of gestation). Preterm infants were subgrouped according to their gestational age as shown in Table 1 . Drug prescriptions have been analysed on a high-level and chemical level of the WHO Anatomic Therapeutic Chemical classification system [11]. The total number of different drugs administered to each patient and exposure rates for each drug group and individual drugs were calculated using SPSS 14.0.

\section{Results}

Patients' descriptives

A total of 183 patients, comprising $55.7 \%$ (102) male and $44.3 \%$ (81) female were included. The mean gestational age was 33.6 weeks (median $=34, \mathrm{SD} \pm 4.66$, minimum $=24$, maximum $=42)$. The majority of patients $(100,54.6 \%)$ were preterm infants; $31.1 \%$ (57) were term infants and $14.2 \%$ (26) were very preterm infants.

Approximately $20 \%$ of the patients were transferred from another hospital. The majority of these patients $(56.8 \%)$ were term infants followed by very preterm infants $(32.4 \%)$.

In total, 10 out of all patients admitted to the study ward died during their stay at the ward (6) or within 6 months of the study (3). One patient died $3 \mathrm{~h}$ after he was admitted to the ward. Two of the patients were term infants.

On average, patients stayed at the ward for 19.4 days $($ median $=11, \mathrm{SD} \pm 24.65$, $\operatorname{minimum}=2$, maximum $=167)$ before discharge or transfer to other wards. 
Table 1 Demographics of the study population

\begin{tabular}{|c|c|c|c|c|c|c|}
\hline & \multirow{2}{*}{$\begin{array}{l}\text { Very preterm neonates } \\
24-27 \text { weeks' } \\
\text { gestation }\end{array}$} & \multicolumn{3}{|c|}{ Preterm neonates } & \multirow{2}{*}{$\begin{array}{l}\text { Term neonates } \\
\geq 37 \text { weeks' } \\
\text { gestation }\end{array}$} & \multirow[t]{2}{*}{ Total } \\
\hline & & $\begin{array}{l}28-30 \text { weeks' } \\
\text { gestation }\end{array}$ & $\begin{array}{l}31-33 \text { weeks' } \\
\text { gestation }\end{array}$ & $\begin{array}{l}34-36 \text { weeks' } \\
\text { gestation }\end{array}$ & & \\
\hline Number of patients & 26 & 22 & 39 & 39 & 57 & 183 \\
\hline Birth weight (g) & 830 & 1,372 & 1,777 & 2,431 & 3,065 & 2,134 \\
\hline SD & \pm 248.9 & \pm 430.6 & \pm 438.7 & \pm 609.1 & \pm 556.5 & \pm 935 \\
\hline Length of hospital stay (days) & 38.8 & 25 & 13 & 17 & 14 & 19.3 \\
\hline $\mathrm{SD}$ & \pm 34.4 & \pm 24.4 & \pm 15.1 & \pm 21.7 & \pm 22.3 & \pm 24.6 \\
\hline Survival (\%) & 96.2 & 100 & 92.3 & 92.3 & 96.5 & 95.1 \\
\hline Percentage of patients $\mathrm{u} / \mathrm{o}$ drug & 100 & 86.40 & 51.30 & 61.50 & 68.40 & 69.90 \\
\hline Number of drugs/u/o drugs & $20 / 9$ & $11 / 3$ & $7 / 2$ & $10 / 4$ & $10 / 4$ & $11 / 4$ \\
\hline $\mathrm{SD}$ & $\pm 11.5 / \pm 5.3$ & $\pm 6.5 / \pm 2.8$ & $\pm 6.9 / \pm 3.3$ & $\pm 10.0 / \pm 5.1$ & $\pm 8.5 / \pm 5.0$ & $\pm 9.6 / \pm 5.0$ \\
\hline Number of prescriptions (total) & 498 & 244 & 278 & 387 & 571 & 1,978 \\
\hline Percentage of prescriptions $\mathrm{u} / \mathrm{o}$ & 41.6 & 24.2 & 26.3 & 33.6 & 36.6 & 34.3 \\
\hline
\end{tabular}

SD: standard deviation score, u: unlicensed, o: off label

Approximately $30 \%$ of patients hospitalised in Erlangen stayed between 1 and 5 days on the study ward, whereas about the same proportion $(29.7 \%)$ of patients transferred from another hospital stayed between 11 and 20 days.

Not surprisingly, very preterm infants stayed longest, e.g. $38.5 \%$ of patients in this group were treated for more than 40 days on the ward. A summary of patient demographics is given in Table 1.

\section{Medication/drug prescriptions}

A total of 1,978 drugs have been prescribed to 181 patients, e.g. $99 \%$ of all patients received at least one drug. The mean number of drugs administered to the patients was 11.1 (median $=8, \mathrm{SD} \pm 9.56$, minimum $=0$, maximum $=45$ ). The majority of patients (35.5\%) received between 0 and 5 drugs, 25 patients (13.7\%) had 20 or more different drugs prescribed, with 40 being the highest number received by 2 patients.

According to the ATC classification system antiinfectives for systemic use $(n=515)$ and drugs for the central nervous system $(n=478)$ have been prescribed most often, followed by drugs for the respiratory system $(n=306)$.

Overall, the drug most often prescribed is phytomenadione/ vitamin $\mathrm{K}(n=163)$ followed by the antibiotics piperacillin $(n=147)$ and tobramycin $(n=146)$.

The majority of drugs showed highest exposure rates in very preterm infants (Table 2).

\section{Anti-infectives}

Among anti-infectives tobramycin $(n=146)$ and piperacillin $(n=147)$ were the drugs most often prescribed. Very preterm infants also frequently received vancomycin, cephalosporins and carbapenems.

Approximately $81 \%$ of all patients were treated with penicillins and $79.8 \%$ received an aminoglycoside antibiotic, e.g. tobramycin. Among the group of patients born between the 28 th and 30th weeks of gestation $100 \%$ were treated with these drugs respectively (Table 2).

\section{Cardiovascular drugs}

Cardiovascular drugs comprising predominantly catecholamines and diuretics were mainly given to very preterm infants. Dobutamine was seen most frequently $(n=58)$. The most frequently used diuretic was furosemide (total exposure rate $21.3 \%$ ). However, very preterm neonates more often received spironolactone $(46.2 \%)$ and hydrochlorothiazide (42.3\%; Table 3$)$.

\section{Central nervous system drugs}

Central nervous system drugs comprising anaesthetics, analgesics, anti-epileptics and psycholeptic drugs, e.g. diazepam and midazolam, showed a high number of prescriptions $(n=448)$, but with a total exposure rate of only $60.7 \%$.

All four therapeutic groups showed highest exposure rates in very preterm neonates (Table 3 ).

Piritramide was the analgesic prescribed most often in general $(n=56,31 \%$ exposure rate) and in very preterm infants $(n=16,61 \%$ exposure rate). Metamizole $(n=43)$ was the second most frequently administered analgesic, but more often to patients born during a later period of gestation. Paracetamol was prescribed rarely. In general, 
Table 2 Exposure rates (in percent) for anatomical levels of the ATC classification by gestational age

\begin{tabular}{|c|c|c|c|c|c|c|}
\hline & \multirow[t]{2}{*}{ Total } & \multirow{2}{*}{ 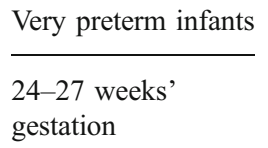 } & \multicolumn{3}{|l|}{ Preterm infants } & \multirow{2}{*}{$\begin{array}{l}\text { Term infants } \\
\geq 37 \text { weeks' } \\
\text { gestation }\end{array}$} \\
\hline & & & $\begin{array}{l}28-30 \text { weeks' } \\
\text { gestation }\end{array}$ & $\begin{array}{l}31-33 \text { weeks' } \\
\text { gestation }\end{array}$ & $\begin{array}{l}34-36 \text { weeks' } \\
\text { gestation }\end{array}$ & \\
\hline Anti-infectives for systemic use & 90.7 & 96.2 & 100 & 82.1 & 84.6 & 94.7 \\
\hline Blood and blood-forming organs & 90.7 & 69.2 & 100 & 94.9 & 92.3 & 93 \\
\hline Nervous system & 60.7 & 96.2 & 54.5 & 35.9 & 56.4 & 66.7 \\
\hline Anaesthetics & 44.8 & 73.1 & 31.8 & 30.8 & 43.6 & 47.4 \\
\hline Analgesics & 37.7 & 65.4 & 18.2 & 12.8 & 43.6 & 45.6 \\
\hline Anti-epileptics & 33.9 & 76.9 & 36.4 & 7.7 & 25.6 & 36.8 \\
\hline Psycholeptics & 52.5 & 92.3 & 40.9 & 30.8 & 51.3 & 54.4 \\
\hline Respiratory system & 60.1 & 84.6 & 90.9 & 48.7 & 56.4 & 47.4 \\
\hline Alimentary tract and metabolism & 53 & 76.9 & 72.7 & 41 & 48.7 & 45.6 \\
\hline Cardiovascular system & 44.8 & 88.5 & 50 & 30.8 & 28.2 & 43.9 \\
\hline Musculo-skeletal system & 39.3 & 69.2 & 40.9 & 20.5 & 38.5 & 38.6 \\
\hline Sensory organs & 9.8 & 23.1 & 9.1 & 10.3 & 5.1 & 7 \\
\hline $\begin{array}{l}\text { Systemic hormonal preparations, } \\
\text { excluding sex hormone }\end{array}$ & 9.3 & 34.6 & 0 & 5.1 & 2.6 & 8.8 \\
\hline
\end{tabular}

only four different analgesic drugs were used on a preterm intensive care unit.

\section{Respiratory system}

Of the respiratory drugs that were given to $60.1 \%$ of all patients, theophylline $(n=95)$ and caffeine citrate $(n=38)$ were most frequently given, followed by surfactant $(n=35)$.

Surfactant was received by $50 \%$ of patients born between the 28th and 30th weeks of gestation and 38.5\% of very preterm infants respectively.

Among the very preterm infants born in the University Hospital Erlangen (14), 71.4\% (10) received surfactant (either Alveofact ${ }^{\circledR}$ or Curosurf $^{\circledR}$ ).

Eighty-nine and a half percent of the patients treated with caffeine also received theophylline intravenously prior to orally applied caffeine, whereas only $35.8 \%$ of the patients initially treated with theophylline received caffeine later on.

\section{Unlicensed/off-label drug prescriptions}

A total of 102 different drugs corresponding to 135 products were analysed. Sixty-three $(62 \%)$ did not have any information regarding their use in patients less than 1 month old, accounting for $34 \%$ of all medication prescribed. Among those, $4(6.3 \%)$ were classified as unlicensed, i.e. 2 were prepared in the hospital pharmacy (caffeine and calcium gluconate) and 2 were imported (indomethacin/ibuprofen iv). The remaining 59 drugs were classified off-label. One hundred percent of anaesthetics and analgesics were found to have no information regarding use in neonates/preterm neonates. On the other hand, 7 out of 15 antibiotics used and 2 out of 6 cardiac drugs (dobutamin and alprostadil) were found to have no information, accounting for $66.3 \%$ of all prescriptions in this group (Fig. 1; Table 4).

Seventy percent of all patients received at least one unlicensed/off-label drug (mean $=4$ per patient, minimum $=0$, maximum $=24)$. All very preterm infants $(100 \%)$ received at least one of these drugs (mean $=9$, minimum $=2$, maximum $=$ 20; Table 1).

\section{Discussion}

This study provides for the first time a detailed overview of the population and the pharmacological treatment given on a neonatal intensive care unit specialised in pre-term neonates in a German University Hospital. Analysing a total of 1,978 prescriptions our data confirm that treatment strategies in this setting are very complex. In particular, very preterm neonates are exposed to a large amount of different drugs; however, for most of the drugs little information regarding their use in this population is available.

We also showed that drug utilisation patterns in very preterm infants are different compared with newborns with a higher gestational age.

In general, our study population represents the clientele of a specialised NICU in Germany, which is shown in the high rate of patients transferred from other hospitals (20.2\%; of which $56.8 \%$ were term infants and $32.4 \%$ 


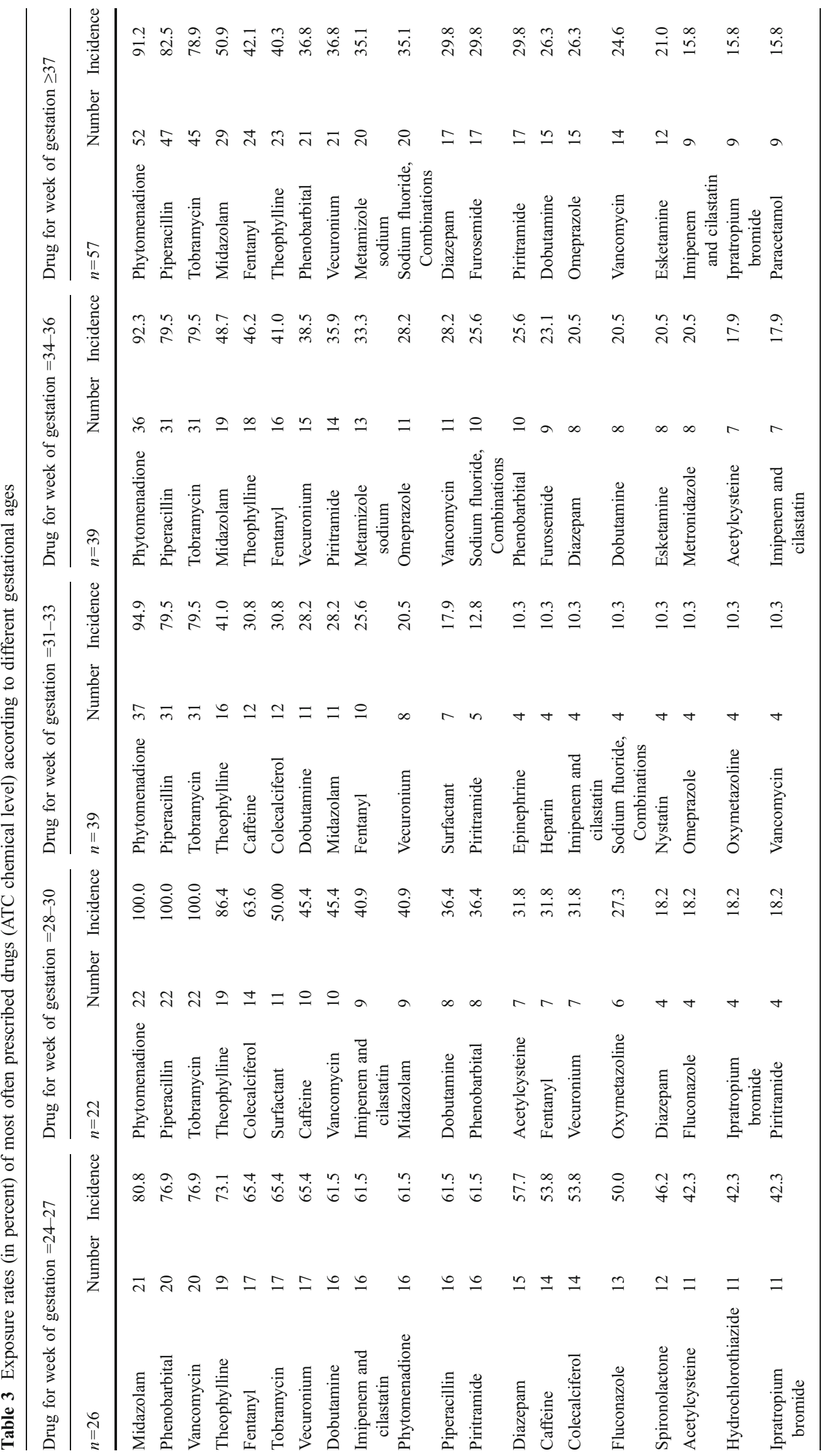




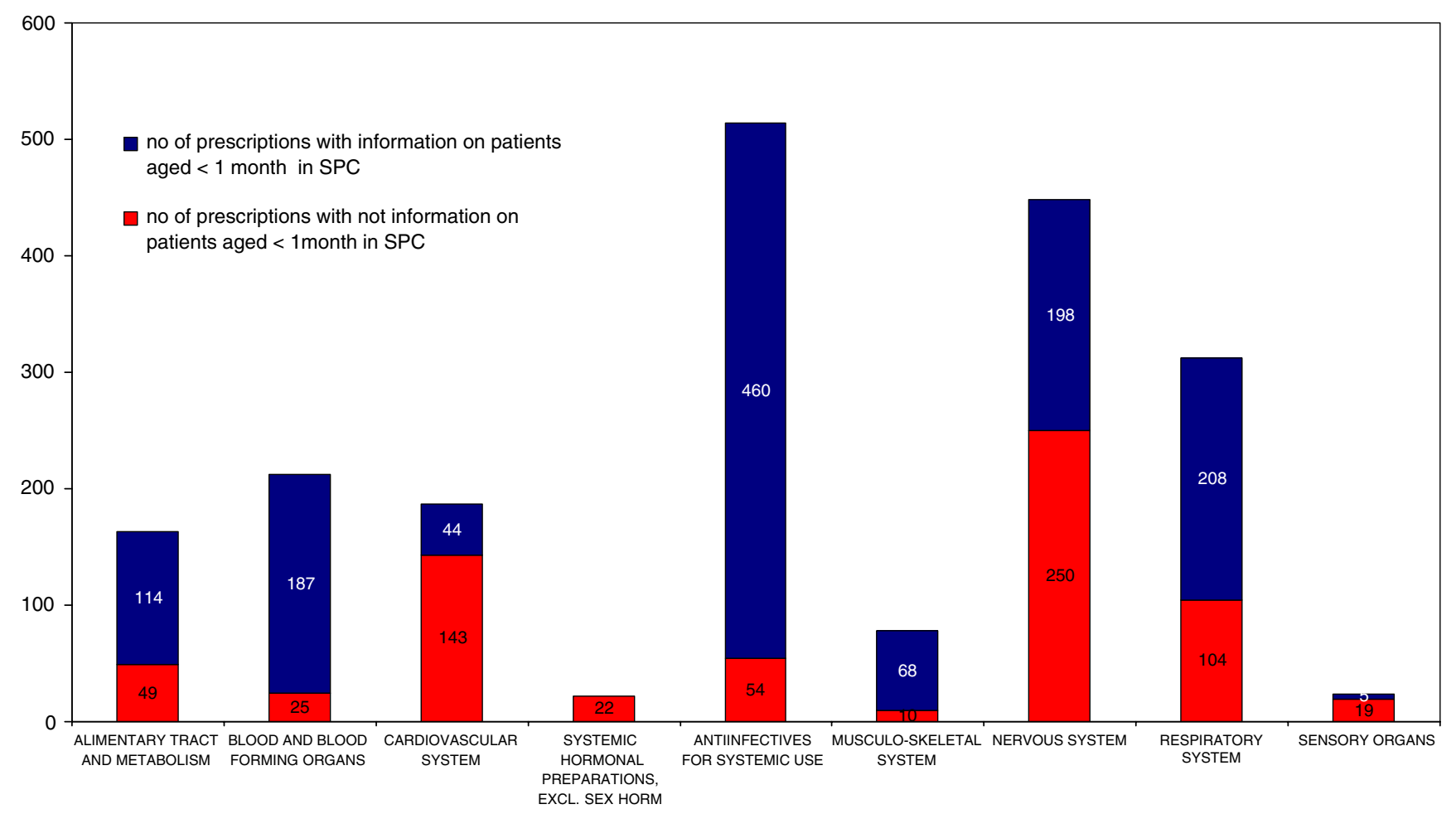

Fig. 1 Proportion of licensed and unlicensed/off-label prescriptions per ATC level

were very preterm infants). This is also reflected in the length of hospital stay, with an average of 19.4 days. A similarly high number (15.4 days) was reported by $\mathrm{Du}$ et al. who conducted their study in an intramural ward in the USA [1].

The mean number of different drugs given to our patients is 11.1 ( $\mathrm{SD} \pm 9.56)$. Previously reported numbers vary between 3.7 [1] and 8.6 [12] drugs per patient [1, 9, 12, 13]. The high number in our study is explained by the specialisation of our study ward and the high proportion of very preterm and preterm infants (69\%). Daniell and Darlow reported data from New Zealand, where even in 1989 the average number was already 14.5 drugs per patient in those with a birth weight less than $1,500 \mathrm{~g}$ [12]. In the USA, Warrier et al. found a lower number with an average of 9.9 drugs per patient given to those born at 24-27 weeks' gestation [4]. Du et al. and Del'Aera et al. report lower numbers; however, only about $50 \%$ of their study populations consisted of preterm neonates $[1,9]$. The lower numbers in other studies
Table 4 Drug groups with most unlicensed/off-label prescriptions

\begin{tabular}{lllc}
\hline & $\begin{array}{c}\text { Number of drugs u/o/ } \\
\text { total number of drugs }\end{array}$ & $\begin{array}{l}\text { Total number } \\
\text { of prescriptions }\end{array}$ & $\begin{array}{l}\text { Percentage of } \\
\text { u/o prescriptions }\end{array}$ \\
\hline Drugs for acid-related disorders & $1 / 1$ & 35 & 100 \\
Drugs used in diabetes & $3 / 3$ & 6 & 100 \\
Antithrombotic agents & $4 / 5$ & 26 & 69.23 \\
Cardiac therapy & $2 / 6$ & 101 & 66.34 \\
Diuretics & $3 / 4$ & 81 & 87.65 \\
Corticosteroids for systemic use & $5 / 5$ & 22 & 100 \\
Anti-bacterials for systemic use & $7 / 15$ & 478 & 10.67 \\
Anti-inflammatory and antirheumatic drugs & $2 / 2$ & 10 & 100 \\
Anaesthetics & $6 / 6$ & 116 & 100 \\
Analgesics & $4 / 4$ & 119 & 100 \\
Anti-epileptics & $3 / 4$ & 73 & 15.1 \\
Respiratory system drugs & $5 / 11$ & 312 & 33.3 \\
Ophthalmologicals & $5 / 6$ & 24 & 79.17 \\
\hline
\end{tabular}


may also be explained because they excluded all routine nursery care items such as vitamin $\mathrm{K}$ prophylaxis and exclusively considered patients born at the institution [1].

\section{Antibiotics}

Undoubtedly, antibiotics are the most frequently used drugs in neonatal intensive care. We observed that $90.7 \%$ of all our study patients were treated with at least one, but mostly two antibiotics. Within the group of very preterm infants $96.2 \%$ and among the preterm infants (28th-30th week of gestation) $100 \%$ of patients received antibiotic treatment. These absolute numbers are in line with the data published from another hospital in Germany by Gortner et al. where the exposure to antibiotics in preterm neonates (24-29 weeks' gestation) was $98.8 \%$ [14]. Similar high exposure numbers for antibiotics are reported from the USA $[1,4]$.

However, looking at individual drugs a great variation with regard to which drugs are used most frequently is apparent. Authors from the UK [15, 16], Australia [17] and the USA $[13,18]$ report gentamicin to be the most frequently used antibiotic. From Italy, Dell'Aera et al. [9] report amikacin and ampicillin to be the most frequently used antibiotic and $\mathrm{Du}$ et al. from the USA report cefotaxime to be the most common agent [1]. Our data show that in Germany tobramycin/piperacillin is the preferred antibiotic for neonates and preterm neonates. This heterogeneity indicates that empiric antibiotic treatment varies among neonatal intensive care units and countries and there are currently no consensus guidelines regarding the choice of empiric antibiotics.

This finding is not surprising; a Cochrane review comparing the antibiotic regimens for suspected late onset sepsis in newborn infants concluded that there is inadequate evidence from randomised trials in favour of any particular antibiotic regimen for the treatment of suspected late onset neonatal sepsis [19]. Consequently, the choice of antibiotic regimes to use depends upon personal experience and hospital policies rather than being guided by comparative clinical studies.

Respiratory drugs and surfactant

Chronic lung disease is the most common lung disease among premature newborns with an increasing incidence as birth weight and gestational age decrease [20]. Surfactant has been shown to be beneficial for the prevention and treatment of respiratory distress syndrome [21-24]. With its use, clinical practice has changed significantly over the last 25 years [25].

Hughes et al. reported a significant increase in surfactant administration between 1994 and 2001 in Northern Ireland [26] and Warrier et al. report from the USA that $100 \%$ of babies born at less than 23 weeks' gestation and $81 \%$ of patients born at 24-27 weeks' gestation (very preterm infants) were given surfactant [4].
In contrast, Lindner et al. [3] recently showed a decrease in surfactant use when comparing its use in the late 1980s and in the early 2000s in various study sites in Germany.

In our study we found that only $38 \%$ of patients born at 24-27 weeks' gestation received surfactant. The reason for this low number might be that as a specialised centre many patients were transferred from other hospitals where surfactant had been given immediately after birth, but had not been documented in the accompanying patient records. Looking at patients born at the University Hospital Erlangen between the 24th and 27 th weeks of gestation, $70 \%$ received surfactant immediately after birth or later on the ward, which is in line with the numbers reported by Lindner et al. [3].

One of the reasons for the heterogeneity of this clinical practice is that the administration of surfactant needs intubation and whether the benefits of prophylactic surfactant are superior to the risks of intubation has not been shown.

Methylxanthines are well accepted therapies for neonatal apnoea; however, adequate data on safety and efficacy are still limited. In our analysis $73.1 \%$ and $53.8 \%$ of patients born at 24-27 weeks' gestation received theophylline and caffeine respectively. Lindner et al. report similar numbers from Germany: in their study, an increase in the use of methylxanthines, e.g. theophylline and caffeine, from $56.7 \%$ to $89.4 \%$ over the period 2001-2004 was observed [3]. In contrast, Warrier et al. from the US report in the same population $41.3 \%$ theophylline and $29.7 \%$ caffeine use [4].

\section{Unlicensed/off-label prescriptions}

Previous studies in neonatal intensive care units found that about $10 \%(9.9-12 \%)$ of prescriptions were unlicensed and about $50 \%(47-79 \%)$ were off-label for age, dosage or indication $[9,15,17,27,28]$.

The percentage of prescriptions found to be unlicensed or off-label is lower in our study (34\%). This is because in contrast to other studies we only investigated the licensing status for age and not for dose and indication. However, looking at the total number of products given on our NICU we found that for $69 \%$ no information on use in neonates and preterm infants was available in the product information. Furthermore, we identified that $69.9 \%$ of all patients and $100 \%$ of very preterm infants received at least one of these prescriptions with median numbers of 4 and 9 respectively. Similar numbers are given in the literature: O'Donnell et al. reported that $80 \%$ of all patients had received at least one $\mathrm{u} / \mathrm{o}$ medicine, whereas Conroy et al. indicated $90 \%$ of patients had done so $[15,17]$.

Surprisingly, we found that there was no information available for anaesthetics and analgesics; hence, all of them were prescribed off-label. The lack of information for these medicines in neonates and preterm neonates clearly contributes to the little prescribing seen in these patients. 
However, a clear increase in the use of analgesics can be seen compared with studies from the 1980s and early 1990s. This reflects the increasing awareness that untreated pain has long-term effects such as developmental retardation and alteration [28]. Nevertheless, our data show that appropriate pain treatment is still neglected in neonatal intensive care on an NICU in Germany, which is not least due to missing data, particularly in very preterm infants.

Considerable differences in the use of analgesics are seen among the countries, e.g. whereas in our ward piritramide is the dominating opioid analgesic, the majority of other authors report morphine to be the opioid of choice. In an Australian study morphine was the second most frequently prescribed drug on an NICU; in contrast, Warrier et al. do not report any analgesics among the 15 most frequently prescribed drugs, which is in line with the Italian data from Del'Aera et al. [4, 9, 17].

Metamizole is the second most frequently used analgesic in our study; however, in the USA and many other countries it is not on the market because of its capacity to induce agranulocytosis and aplastic anaemia.

\section{Conclusion}

We provide an unique and detailed overview of the drugs used on a specialised NICU in Germany. The data show that there are many similarities, but also differences in treatment regimes compared with the few previously published studies from Germany and other countries.

In summary, this reflects the uncertainties in neonatal drug therapy due to a lack of data and confirms the need for future larger scale randomised controlled trials. A large proportion of patients are treated with non-licensed medicines, e.g. every very preterm baby on the NICU receives at least one drug for which no information on safety and efficacy is available. In particular, cardiovascular drugs, including diuretics and anaesthetics/analgesics are of major concern. The European regulatory authorities have recognised paediatric therapeutic needs and some of the drugs frequently given to very preterm infants, such as midazolam, fentanyl, dobutamine or hydrochlorothiazide, are already on their list of off-patent drugs [29]. Well-designed and powered multicentre and cross-nationality studies will have to be conducted as the key to successful improvement of drug therapy in neonates and preterm neonates in particular.

\section{References}

1. Du W, Warrier I, Tutag Lehr V, Salari V, Ostrea E, Aranda JV (2006) Changing patterns of drug utilization in a neonatal intensive care population. Am J Perinatol 23:279-285
2. Saigal S, Doyle LW (2008) An overview of mortality and sequelae of preterm birth from infancy to adulthood. Lancet 371:261-269

3. Lindner U, Hilgendorff A, Frey G, Gortner L (2008) Drug utilisation in very preterm infants: any changes during the past decade? Klin Padiatr 220:238-242

4. Warrier I, Du W, Natarajan G, Salari V, Aranda J (2006) Patterns of drug utilization in a neonatal intensive care unit. J Clin Pharmacol 46:449-455

5. European Commission (2006) Regulation (EC) No. 1901/2006 of the European Parliament and of the Council on medicinal products for paediatric use. European Commission, Brussels

6. Neubert A, Planner C, Cranswick N (2008) The new European regulation on pediatric medicines: safety and ethics perspectives. Paediatr Drugs 10:147-149

7. Senate and House of Representatives of the United States of America (2003) Pediatric Research Equity Act of 2003

8. World Health Organisation (2007) Making medicines child size. World Health Organisation, Geneva

9. Dell'Aera M, Gasbarro AR, Padovano M, Laforgia N, Capodiferro D, Solarino B, Quaranta R, Dell'Erba AS (2007) Unlicensed and off-label use of medicines at a neonatology clinic in Italy. Pharm World Sci 29:361-367

10. Turner S, Nunn AJ, Fielding K, Choonara I (1999) Adverse drug reactions to unlicensed and off-label drugs on paediatric wards: a prospective study. Acta Paediatr 88:965-968

11. WHO Collaborating Centre for Drug Statistics Methodology. Anatomical-Therapeutical-Chemical (ATC) Classification-Index and Guidelines. World Health Organisation, Geneva

12. Daniell AJ, Darlow BA (1989) Audit of drug usage in a regional neonatal intensive care unit. Aust Paediatr J 25:207-210

13. Lesko SM, Epstein MF, Mitchell AA (1990) Recent patterns of drug use in newborn intensive care. J Pediatr 116:985-990

14. Gortner L, Bernsau U, Brand M, Hellwege HH, Hieronimi G, Jorch G, Reiter HL, Versmold H (1991) Drug utilization in very premature infants in neonatal intensive care units. Dev Pharmacol Ther 17:167-171

15. Conroy S, McIntyre J, Choonara I (1999) Unlicensed and off label drug use in neonates. Arch Dis Child Fetal Neonatal Ed 80:F142-F144

16. Turner MA, Lewis S, Field D (2008) Priorities in neonatal medicines research: a scoping exercise, Abstract, Biannual Meeting ESDPP, Rotterdam

17. O’Donnell CP, Stone RJ, Morley CJ (2002) Unlicensed and offlabel drug use in an Australian neonatal intensive care unit. Pediatrics 110:e52

18. Clark RH, Bloom BT, Spitzer AR, Gerstmann DR (2006) Reported medication use in the neonatal intensive care unit: data from a large national data set. Pediatrics 117:1979-1987

19. Gordon A, Jeffery HE (2005) Antibiotic regimens for suspected late onset sepsis in newborn infants. Cochrane Database Syst Rev CD004501

20. Cunha GS, Mezzacappa FF, Ribeiro JD (2003) Maternal and neonatal factors affecting the incidence of bronchopulmonary dysplasia in very low birth weight newborns. J Pediatr (Rio J) 79:550-556

21. Sweet DG, Halliday HL (2000) A risk-benefit assessment of drugs used for neonatal chronic lung disease. Drug Saf 22:389-404

22. Stevens TP, Blennow M, Myers EH, Soll R (2007) Early surfactant administration with brief ventilation vs. selective surfactant and continued mechanical ventilation for preterm infants with or at risk for respiratory distress syndrome. Cochrane Database Syst Rev CD003063

23. Soll RF, Morley CJ (2001) Prophylactic versus selective use of surfactant in preventing morbidity and mortality in preterm infants. Cochrane Database Syst Rev CD000510 
24. Yost CC, Soll RF (2000) Early versus delayed selective surfactant treatment for neonatal respiratory distress syndrome. Cochrane Database Syst Rev CD001456

25. Been JV, Zimmermann LJ (2007) What's new in surfactant? A clinical view on recent developments in neonatology and paediatrics. Eur J Pediatr 166:889-899

26. Hughes JL, McCall E, Alderdice F, Jenkins J (2006) More and earlier surfactant for preterm infants. Arch Dis Child Fetal Neonatal Ed 91:F125-F126
27. Avenel S, Bomkratz A, Dassieu G, Janaud JC, Danan C (2000) The incidence of prescriptions without marketing product license in a neonatal intensive care unit. Arch Pediatr 7:143-147

28. Knoeppel C, Klinger O, Soergel M, Seyberth HW, Leonhardt A (2000) Anwendung von Medikamenten außerhalb der Zulassung oder ohne Zulassung bei Kindern. Monatsschr Kinderheilkd 148:904-908

29. European Medicine Agency (2008) Priority list of off-patent medicinal products for paediatric studies. EMEA, London 